that patients with severe psychosis may be dramatically medication-resistant, unless they have used threshold dosing they do not know that the sensitivity of the patient to antipsychotic medication increases as their mental state improves, allowing a reduction in dose with maintained efficacy. It is worth remembering that BNF limits are usually established in accessible and responsive out-patient populations with moderate symptoms. Practising clinicians treat many patients who do not come from this population and may find themselves with a difficult choice: polypharmacy or prescription outside $B N F$ limits.

1 Taylor D. Antipsychotic polypharmacy - confusion reigns. Psychiatrist 2010; 34: 41-3.

2 Agid O, Mamo D, Ginovart N, Vitcu I, Wilson AA, Zipursky RB, et al. Striatal vs extrastriatal dopamine $D 2$ receptors in antipsychotic response - a double-blind PET study in schizophrenia. Neuropsychopharmacology 2006; 32: 1209-15.

3 Searle GF. Optimising neuroleptic treatment for psychotic illness. Psychiatr Bull 1998; 22: 548-51.

Geoffrey F. Searle is Consultant Psychiatrist, Dorset Healthcare NHS Foundation Trust, UK, email: geoff.searle@dhft.nhs.uk

doi: $10.1192 / \mathrm{pb} .34 .6 .259 \mathrm{~b}$

\section{The importance of early and accurate diagnosis}

The excellent article by Chan \& Sireling ${ }^{\top}$ about the recent increase in public awareness of bipolar disorder mirrors our own experience in research and practice, and highlights important issues for health services.

This article is very timely because there is ongoing debate about the extent to which bipolar disorder may be over- or underdiagnosed. ${ }^{2,3}$ Both over- and underdiagnosis occur and are problematic. Some people may be inappropriately labelled, whereas others who would benefit from the diagnosis are missed. Optimal treatment of depression is different in bipolar and unipolar disorders. This is one of many examples in psychiatry where making an early and correct diagnosis is highly likely to have a very direct and important effect on the quality of care offered to, and quality of life experienced by, a patient. ${ }^{4}$

Chan \& Sireling highlight new cases of bipolar disorder from the primary care setting. Preliminary data from our ongoing studies of primary care patients with depression suggest that bipolar (i.e. manic/hypomanic) features are relatively common in this group (unpublished data; available from the authors on request). In our wider research in individuals with both bipolar and unipolar mood disorders, we have found that those with a diagnosis of recurrent unipolar depression who have a history of mild manic symptoms tend to respond less well to antidepressants. ${ }^{5}$

Inevitably, increasing awareness of any illness has the potential to lead to overdiagnosis and this could cause problems for the patient as well as for services. Thus, a balance must always be struck between the need to increase awareness appropriately among patients, public and clinicians, while not causing a tsunami of uncritical overdiagnosis and self-labelling. As psychiatrists we must ensure we are pragmatic and put the patient's well-being at the centre of decision-making. This will require us to have knowledge of the developing evidence base, make a comprehensive diagnosis based on a detailed lifetime history of both depressed and manic mood (including asking an informant), and have an awareness of the boundaries of clinically relevant symptomatology.

1 Chan C, Sireling L. 'I want to be bipolar' ... a new phenomenon. Psychiatrist 2010; 34: 103-5.

2 Zimmerman $M$. Is underdiagnosis the main pitfall in diagnosing bipolar disorder? No. BMJ 2010; 340: c855.

3 Smith DJ, Ghaemi N. Is underdiagnosis the main pitfall when diagnosing bipolar disorder? Yes. BMJ 2010; 340: c854.

4 Craddock N, Antebi D, Attenburrow MJ, Bailey A, Carson A, Cowen P, et al. Wake-up call for British psychiatry. Br J Psychiatry 2008; 193: 6-9.

5 Smith DJ, Forty L, Russell E, Caesar S, Walters J, Cooper C, et al. Subthreshold manic symptoms in recurrent major depressive disorder are a marker for poor outcome. Acta Psychiatr Scand 2009; 119: 325-9.

Nick Craddock is Professor of Psychiatry, Ian Jones is Senior Lecturer in Perinatal Psychiatry and Daniel J. Smith is Senior Lecturer in Psychiatry, Department of Psychological Medicine and Neurology, School of Medicine, Cardiff University, UK, email: craddockn@cardiff.ac.uk

doi: $10.1192 / p b .34 .6 .260$

\section{The suggested obligation to declare mental health issues to employer}

I enjoyed Chan \& Sireling's article ${ }^{1}$ considerably, although | must write in response to the comments about obligatory declarations of mental health to employers.

Although there is little doubt that in most cases employers need to be aware of a bipolar affective condition in employees, this is not always appropriate. Indeed, best practice requires employers to require submission of preemployment forms not to themselves but to an occupational health professional. Those with a bipolar condition should almost always be invited to a review with an occupational physician.

At that point, and that point only, is it appropriate for there to be discussion as to what is to be shared with the employer. At the very least such a consultation is likely to head in the direction of advice to an employer that the employee has a condition which may require adjustment under the Disability Discrimination Act. What an occupational physician tells an employer is, however, subject to their own professional judgement and indeed ultimately down to what the employee feels is appropriate.

Occupational medicine is a small specialty, although a valuable one, not least for psychiatric patients, for whom we can do a great deal.

1 Chan C, Sireling L. 'I want to be bipolar' ... a new phenomenon. Psychiatrist 2010; 34: 103-5.

Clive H. Morgan is Occupational Physician, Cardiff, UK, email: chmorgan@doctors.org.uk

doi: 10.1192/pb.34.6.260a

\section{Narrative triad and philosophy}

Wallang ${ }^{1}$ provides a stimulating and insightful consilience of wide-ranging ideas. This is what a journal should be about, not the repetitive reductive statistics cobbled together to further 